\title{
Erosion number and area progression in the wrists and hands of rheumatoid patients: a quantitative microfocal radiographic study
}

\author{
J C BUCKLAND-WRIGHT, G S CLARKE, AND S R WALKER
}

From the Macroradiographic Research Unit, Anatomy Department, United Medical and Dental Schools of Guy's and St Thomas's Hospitals, Guy's Campus, London Bridge

SUMMARY Microfocal radiography has been used to evaluate the relation between erosion number and erosion area in the hands and wrists of 51 patients with early to moderately advanced rheumatoid arthritis. The hands of these patients showed different patterns of erosion progression, in terms of the relation between changes in number and area, and included those showing a decrease in one or both of the erosion parameters. The mean number of erosions in the group increased between the first and second visits. By the third visit (a mean of 48 months from the onset of symptoms) the mean number of erosions in the wrist and hand of the group had approached a constant value of 75 erosions. Over the same period the mean erosion area of the group continued to increase. Measurement of changes in erosion area is a more sensitive indicator of erosion progression than erosion number, both within the group and in individual patients.

The radiographic assessment of disease progression in rheumatoid arthritis (RA) is based on either the method of Sharp et al or that of Larsen et al. ${ }^{1-3}$ Both methods score the extent of joint destruction. Sharp scores each joint on the basis of the number of erosions up to a total of four; a maximum score of five is given when the joint is more severely damaged. Larsen's system compares the patient's radiograph with a series of reference films graded $0-5$. This assessment is a global one and is influenced by the size of the lesions as well as their number. ${ }^{2}{ }^{3}$

Although it is becoming widely accepted that the enlargement of erosions rather than the increase in erosion number is most relevant to the radiological assessment of progression in $\mathrm{RA},{ }^{3}$ the relation between changes in number and size has yet to be evaluated. In this study a group of patients with early to moderately advanced RA was assessed by quantitative microfocal radiography ${ }^{4-6}$ over an 18 month period. At six-monthly intervals each patient had the number and size of erosions in the right and left wrist and hand measured and the changes

Accepted for publication 26 May 1988.

Correspondence to Dr J C Buckland-Wright, Department of Anatomy, Guy's Hospital, London Bridge, SE1 9RT. occurring between successive $x$ ray examinations calculated.

\section{Patients and methods}

Eighty patients with early to moderately advanced RA (Larsen ${ }^{2}$ grade 0 to 2 ) were recruited from the rheumatology department at Guy's Hospital for macroradiographic assessment. Patients were $x$ rayed every six months over a period of 18 months, totalling four visits. Only patients for whom there were complete numerical data from four $x$ ray examinations were included in the statistical analysis. These numbered 51 (19 men, 32 women), of whom six were left handed. The mean (SD) time from disease onset to the first $x$ ray was 36 (46) months. The mean (SD) age at onset was 55 (12) years.

The preparation of the macroradiographs, their examination, and measurement have been described elsewhere. ${ }^{4-6}$ The appearance of erosions in the macroradiographs has been described previously ${ }^{6} 7$ and agrees with accounts based on detailed radiopathological examination of material obtained at necropsy. ${ }^{8}$ The lesions appear as small areas of radiolucency occurring beneath the subperiosteal or subchondral bone. Progression of the lesion leads to 
the thinning of the cortical plate with focal discontinuity or gaps. The endosteal margin is defined by the greater radiodensity of the trabecula bordering the lesion. The edges of an erosion, thus outlined, were used in the measurement of its size. The accuracy and reproducibility of the methods of measurement have been evaluated ${ }^{9}$ and show that the change in the size of the $x$ ray features due to disease, during the period of the study, was markedly greater than that attributable to errors of measurement. From the macroradiographs of each patient the total number and total area of erosions were obtained for both wrists and hands at each of the four $x$ ray examinations, by summating the measurements recorded at the 142 erosion sites at each extremity. ${ }^{7}$ These sites are located at the medial and lateral juxtaligamentous and subchondral regions of each articular area in the wrist and the juxta-articular and juxtaligamentous sites in the hand joints. ${ }^{7}$

STATISTICAL ANALYSIS

The SPSS-X statistics package, ${ }^{10}$ together with specially prepared programs, were used for the statistical analysis. The statistical significance of changes in the total number and total area of erosions which occurred in each hand between visits was calculated for each patient. This analysis was based upon the accuracy of erosion identification (coefficient of variation $4 \cdot 8 \%$ ) and area

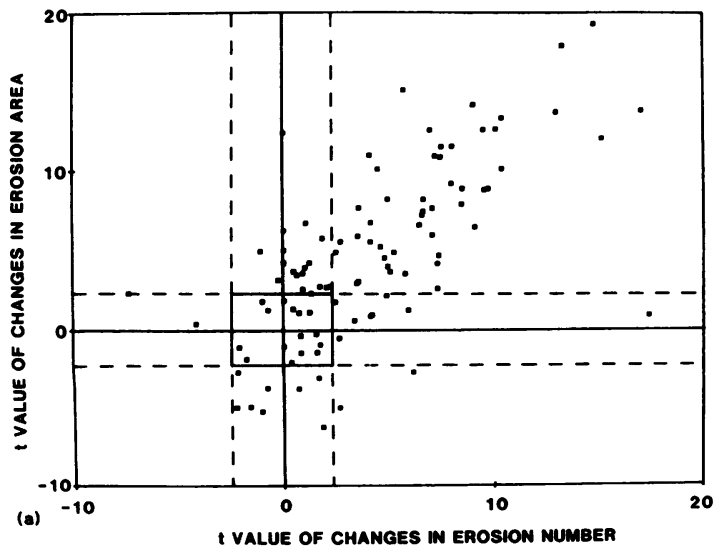

Fig. 1 Graph of the $t$ values for the change in total erosion number and area in the wrists and hands of each patient occurring between successive visits: (a) visits 1-2; (b) visits 2-3; and (c) visits 3-4. The broken lines parallel to the axes mark the $95 \%$ confidence limits for the two parameters. The box formed by the intersection of the two sets of confidence limits enclose points representing hands where there are no statistically significant changes. For details see text.
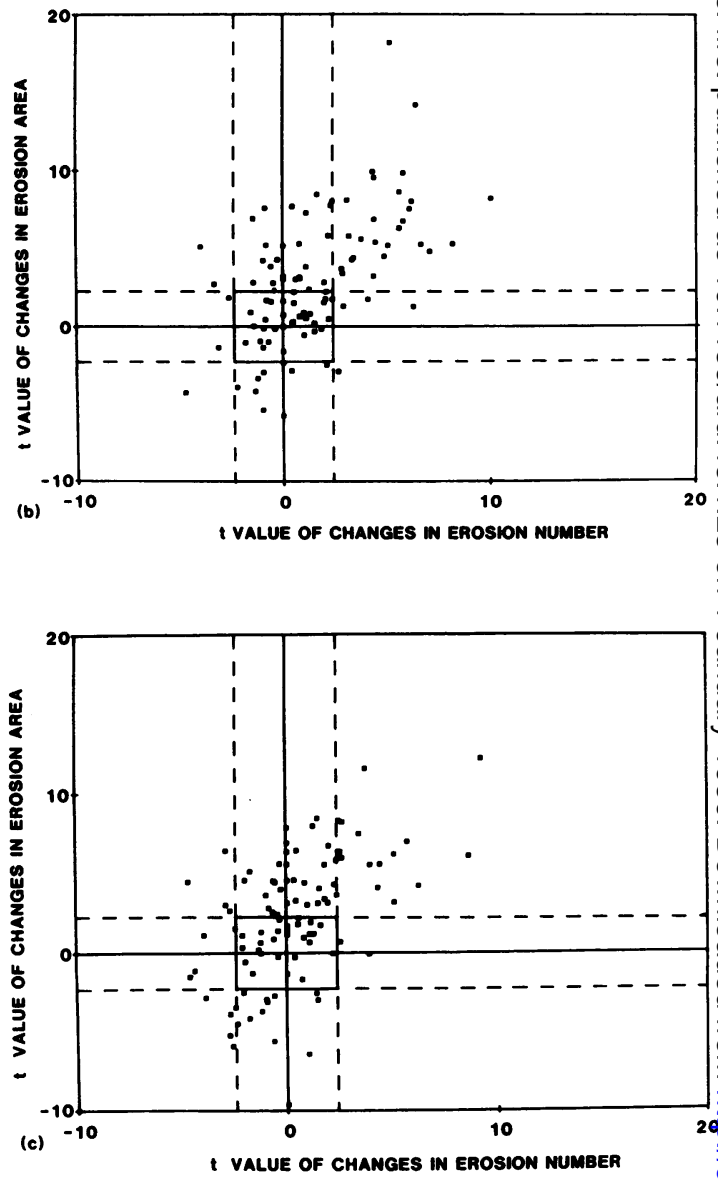

measurements (coefficient of variation $7 \cdot 5 \%$ ) in macroradiographs. ${ }^{9}$ The changes between visitso were expressed as $t$ values; a significant level of $95 \%$ corresponded to a $t$ value of $2 \cdot 3$. A scatter graph (Fig. 1) was prepared to illustrate the relation between the changes in number and area for each hand occurring between visits for each patient. N Those changes that reached $95 \%$ significance lever were tabulated (Table 1).

\section{Results}

The scattergraphs show the relation between changes in total number and total area for each hand? occurring between successive $x$ ray examinations (Figs 1a, b, and c). The broken lines parallel to the $x$ and y axes mark the $95 \%$ confidence limits for these? parameters. The box formed by the intersection of the two sets of confidence limits encompasses thoser points representing hands where there were no 
Table 1 A summary of the data in the graphs (Figs 1a, $b$, and $c$ ), recording for the periods between successive $x$ ray examinations the number of hands of patients in each separate region corresponding to the nine different combinations of changes between erosion number and area.

\begin{tabular}{|c|c|c|c|c|c|}
\hline & \multirow[t]{2}{*}{ Patterns of erosion ${ }^{*}$} & & \multicolumn{3}{|c|}{ Visit interval } \\
\hline & & & $1-2$ & $2-3$ & $3-4$ \\
\hline $\begin{array}{l}\text { Increase in } \\
\text { area }\end{array}$ & $\begin{array}{l}\text { Increase in number } \\
\text { No change in number } \\
\text { Decrease in number }\end{array}$ & $\begin{array}{r}{[\mathrm{A}]} \\
{[\mathrm{B}]} \\
{[\mathrm{C}]} \\
\text { Total }\end{array}$ & $\begin{array}{r}48 \\
18 \\
1 \\
67\end{array}$ & $\begin{array}{r}27 \\
23 \\
2 \\
52\end{array}$ & $\begin{array}{r}17 \\
30 \\
4 \\
51\end{array}$ \\
\hline $\begin{array}{l}\text { No change in } \\
\text { area }\end{array}$ & $\begin{array}{l}\text { Increase in number } \\
\text { No change in number } \\
\text { Decrease in number }\end{array}$ & $\begin{array}{r}{[\mathrm{D}]} \\
{[\mathrm{E}]} \\
{[\mathrm{F}]} \\
\text { Total }\end{array}$ & $\begin{array}{r}8 \\
16 \\
1 \\
25\end{array}$ & $\begin{array}{r}4 \\
33 \\
2 \\
39\end{array}$ & $\begin{array}{r}2 \\
27 \\
4 \\
33\end{array}$ \\
\hline $\begin{array}{l}\text { Decrease in } \\
\text { area }\end{array}$ & $\begin{array}{l}\text { Increase in number } \\
\text { No change in number } \\
\text { Decrease in number }\end{array}$ & $\begin{array}{r}{[\mathrm{G}]} \\
{[\mathrm{H}]} \\
{[\mathrm{I}]} \\
\text { Total }\end{array}$ & $\begin{array}{r}2 \\
8 \\
0 \\
10\end{array}$ & $\begin{array}{r}1 \\
9 \\
1 \\
11\end{array}$ & $\begin{array}{r}0 \\
11 \\
7 \\
18\end{array}$ \\
\hline
\end{tabular}

${ }^{*}[\mathrm{~A}]$ New erosions form and existing lesions increase in area; [B] no new erosions form and existing lesions increase in area; [C] adjacent erosions amalgamate owing to increase in erosion area, leading to a reduction in erosion number; [D] new erosions form, existing lesions decrease in area-that is, the area remains constant; $[E]$ no net change in number and area of erosions; $[F]$ of the existing erosions, some remineralise and are no longer detectable radiologically and others continue to increase in areathat is, the area remains constant; $[G]$ overall decrease in erosion area is greater than the increase in area associated with the formation of new erosions; $[\mathrm{H}]$ existing erosions decrease in area; [I] remineralisation and loss of radiographically detectable erosions.

statistically significant changes in erosion number and area. The broken lines, extending beyond the box, subdivide the graph into a further eight regions, representing the possible combinations between changes in number and area. The points directly above and below the box correspond to an increase and decrease in erosion area with no change in erosion number respectively. Those points, directly to the left and right of the box correspond to a decrease and increase in erosion number with no change in erosion area respectively. The points within the remaining four regions correspond to hands in which there are changes in both erosion number and area. Table 1 summarises the findings of these graphs.

Figure 1a shows that a closer correspondence existed between the changes in erosion number and area occurring between first and second visits than in graphs of the subsequent visits (Figs $1 \mathrm{~b}$ and c). Furthermore, the magnitude of the changes was greater between the first and second visits than subsequently. Table 1 shows that between the first and second visits most of the cases showed an increase in erosion formation, of which 48 increased in both number and area, 18 in area only and eight in number only. At subsequent visits fewer hands showed significant change. The number of hands showing a significant increase in erosion number in the group declined over the three visits (from 58 to 32 to 19), whereas the increase in erosion area tended towards a constant (total 67, 52, 51). Throughout the study hands of some patients showed a reduction in the number and size of erosions. The number of these hands increased with time.

Figure 2 clarifies these observations by illustrating the average total number and average total area of erosions in the group of patients with RA plotted against time in terms of the time since the first $x$ ray examination. The graph shows that between the first and second visit the percentage change in erosion number and area was $11 \%$ and $19 \%$, between the second and third visits $6 \%$ and $13 \%$, and between the third and fourth visits $0 \%$ and $11 \%$ respectively. By the end of the third visit (48 months from the onset of symptoms in the group) it would appear that the average erosion number of the group had become constant at 75 erosions per wrist and hand. An analysis of variance showed that there was a significant difference $(p<0.05)$ in the average total erosion number of the group of patients between the first and subsequent three visits. The absence of

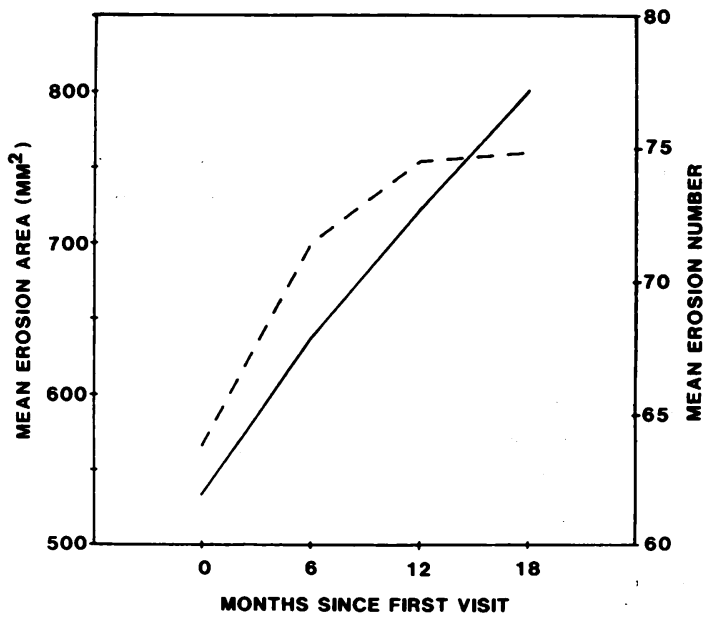

Fig. 2 Change in the average total number (broken line) and average total area (solid line) of erosions in the group of rheumatoid patients plotted against time since the first $x$ ray examination. 
significant differences between the last three visits confirms the reduction in erosion number progression. By contrast, the changes in the average total erosion area were found to be significantly different $(p<0.05)$ between visits 1 and 3,1 and 4 , and between visits 2 and 4 , indicating continuing erosion area progression.

\section{Discussion}

The high magnification and resolution of microfocal radiography permit measurements of structures as small as $35 \mu \mathrm{m}$ and enable the accurate measurement of changes in the number and size of lesions in the rheumatoid wrist and hand. ${ }^{9}$ Analysis of the radiographs in this study indicates that many patterns of erosion development can be found within the wrist and hand of this group of patients (Fig. 1 and Table 1).

As the study progressed evidence of remineralisation tended to be found more frequently and the net disease progression tended to decline. In this instance microfocal radiography detected erosion repair as a decrease in erosion area. This was observed either as a sclerotic margin surrounding an erosion or as a remineralisation of the pre-existing trabeculae at the endosteal margins of the erosion, or both. In addition, the disrupted cortical margin of some erosions remineralised. Owing to these processes erosions were no longer radiologically detectable.

Within this group of patients with RA the mean erosion number and area changed at a similar rate between first and second visits. Over the subsequent period of the study the rates diverged. By the third $x$ ray examination the mean number of erosions in the wrist and hand approached a constant of 75 erosions. At this period of the study most of the hands investigated showed no change in erosion number. The remaining patients were about evenly distributed between those showing an increase and those showing a decrease in erosion number. Over the same period the rate of change of erosion area for the group showed a slight decline, but in most hands erosions continued to enlarge. Within the period of the study there was a gradual increase in the proportion of hands showing no change or a reduction in erosion area.

In this group of patients with RA examination of the erosion number data alone would have led to the conclusion that disease progression had largely ceased by the third $x$ ray ( 48 months from the onset of symptoms in the group). The changes in area in a given hand were generally more significant than those of number, however. Consequently in the $x$ ray analysis of disease progression in a group of

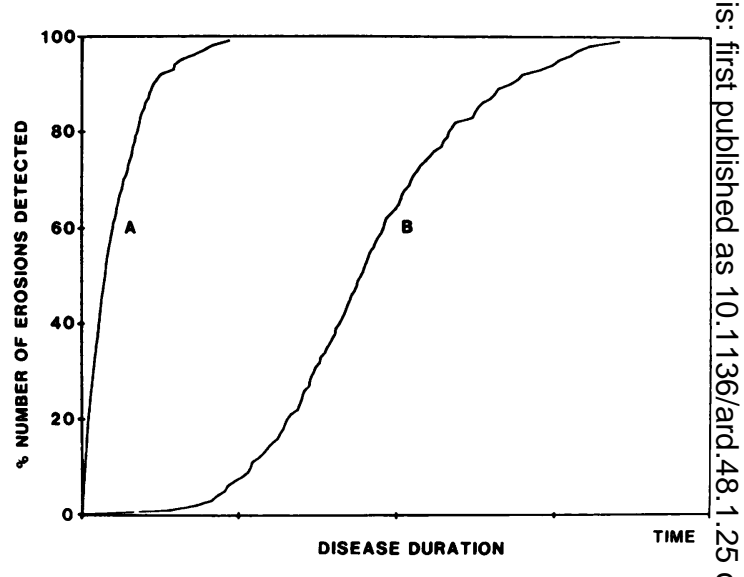

Fig. 3 Results from the computer model of $x$ ray techniques of high (curve A) and low (curve B) sensitivity, illustrating their ability to detect erosions. The number of erosions detected is expressed as a percentage of the number of erosion sites scanned. The severity of bone destruction is expressed in terms of time since the onset of disease.

rheumatoid patients changes in erosion area must beo used in preference to number.

The decrease in erosion number progression fairly early on in the disease process (Fig. 2) is in contrast $\frac{}{\varnothing}$ with the findings of conventional radiography, $\stackrel{\square}{\rightarrow}$ where erosion numbers increased over a 16 yearö period. ${ }^{11}$ A computer model was developed to test the hypothesis that this difference was due to the different sensitivities of the two $x$ ray techniques. Figure 3 illustrates the results. Although the model $\frac{\oplus}{2}$ is an oversimplification as it assumes that erosion. progression is linear and uniform, nevertheless, it 3 . does illustrate the difference in the results from $x$ rayo methods of differing sensitivities. The patterns derived from the model for low sensitivity (Fig. 3B) match the findings described for erosion progression? using standard radiography ${ }^{11}$ and for high sensitivityo (Fig. 3A) the findings for microfocal radiography described here.

The sensitivity of the changes in erosion area as an measure of disease progression described here N confirms the observations and findings of Larsen $\omega$ and his colleagues ${ }^{2} 3$ and emphasises the need to examine the internal organisation of bones and the changes therein rather than simply examining cortical defects. The limitation of this study is that ${ }^{-}$ the patient's treatment was variable and not ${ }_{0}^{-}$ consistent over the study period, thus preventing any conclusions being drawn as to what effect it $\frac{O}{\mathbb{Q}}$ might have had on erosion progression. The effect $\varrho$ of therapeutic intervention on erosion progression is being evaluated, however, in a study currently in 
progress. In the study reported here disease progression was analysed in terms of the total changes in erosion number and area in the wrists and hands of patients. Whether these measurements accurately represent the mechanisms involved in disease progression will be evaluated by a more detailed examination of the changes occurring in individual erosion sites.

We wish to thank Dr R Grahame, Professor G S Panayi, and Dr T Gibson for their cooperation in providing the patients for $x$ ray examination. This work was supported by the Arthritis and Rheumatism Council and by May and Baker (for one of us (GSC)). We would also like to thank Mrs B Clark for typing the manuscript.

\section{References}

1 Sharp J T, Lidsky M D, Collins L C, Moreland J. Methods of scoring the progression of radiological changes in rheumatoid arthritis. Arthritis Rheum 1971; 14: 706-20.

2 Larsen A, Dale K, Eek M. Radiographic evaluation of rheumatoid arthritis and related conditions by standard reference films. Acta Radiol /Diagn] (Stockh) 1977; 18: 481-91.
3 Larsen A, Dale K. Standardized radiological evaluation of rheumatoid arthritis in therapeutic trials. In: Dumonde D C, Jasani $\mathrm{M}$ K, eds. Recognition of anti-rheumatic drugs. Lancaster: MTP Press, 1978: 285-92.

4 Buckland-Wright $\mathrm{J}$ C. X-ray assessment of activity in rheumatoid disease. Br J Rheumatol 1983; 22: 3-10.

5 Buckland-Wright $\mathrm{J} \mathrm{C}$. Advances in the radiological assessment of rheumatoid arthritis. BrJ Rheumatol 1983; 22 (suppl): 34-43.

6 Buckland-Wright J C. Microfocal radiographic examination of erosions in the wrist and hands of patients with rheumatoid arthritis. Ann Rheum Dis 1984; 43: 160-71.

7 Buckland-Wright J C, Walker S R. Incidence and size of erosions in the wrist and hand of rheumatoid patients: a quantitative microfocal radiographic study. Ann Rheum Dis 1987; 46: 463-7.

8 Resnick D, Niwayama G. Diagnosis of bone and joint disorders. Vol 2. Philadelphia: Saunders, 1981: 906-1007.

9 Buckland-Wright J C, Carmichael I, Walker S R. Quantitative microfocal radiography accurately detects joint changes in rheumatoid arthritis. Ann Rheum Dis 1986; 45: 379-83.

10 SPSS-X Inc. SPSS-X users guide. New York: McGraw-Hill, 1987.

11 Sharp J T. Radiographic evaluation of the course of articular disease. Clin Rheum Dis 1983; 9: 541-57. 